\title{
SUPREMO TRIBUNAL FEDERAL E SUA FUNÇÃO INTERPRETATIVA: O PAPEL DO SUPREMO TRIBUNAL FEDERAL SOB A PERSPECTIVA DA TEORIA DO INTERPRETANTE
}

\author{
Diva Alves Costa Neta ${ }^{1}$ \\ Laís Alves Camargos ${ }^{2}$
}

Resumo: Este artigo analisa o papel exercido pelo Supremo Tribunal Federal a partir de algumas pesquisas que estudaram seu papel interpretativo. A partir delas foram analisadas a posição que este tribunal vem tomando, a maneira como ele interpreta a Constituição e como isso afeta o ordenamento jurídico. Foi utilizada a teoria do interpretante de Edward Lopes que toma a interpretação como um fato da leitura, dessa forma o leitor também detém o poder sobre o texto extraído do discurso. A partir dos postulados epistemológicos da teoria semântica são problematizadas a interpretação, o papel do interpretante e a atuação do STF.

Palavras-chave: Interpretação; Supremo Tribunal Federal; Semiologia; Teoria do interpretante; Papel interpretativo do STF.

\section{SUPREMO TRIBUNAL FEDERAL AND ITS INTERPRETATIVE AGENCY:}

\section{THE SUPREMO TRIBUNAL FEDERAL'S ROLE FROM THE PERSPECTIVE OF THE INTERPRETER'S THEORY}

\begin{abstract}
This article studies the role of the Supremo Tribunal Federal through a few researches that studied its interpretative role. From those it was analyzed the stand taken by this court, the way it interpretates the constitution and how this afects the rule of law. It was used the teoria do interpretante by Edward Lopes which takes the interpertation as a reading fact, so the reader also detains power over the text extracted from the speech. From the semantic theory's epistemological postulates there are problematized the interpretation, the interpreter's role and the STF agency's.
\end{abstract}

Keywords: Interpretation. Supremo Tribunal Federal. Semiotics. Interpreter's theory. STF's interpretative role.

\footnotetext{
${ }^{1}$ Mestranda em Direito Público pela Universidade FUMEC. Especialista em Direito Público pela PUC Minas. Bacharel em Direito pela PUC Minas e em Letras pela UFMG. Advogada.

${ }^{2}$ Mestranda em Direito Público pela Universidade FUMEC. Especialista em Direito Processual Civil. Assessora do Tribunal de Justiça de Minas Gerais.
} 


\section{INTRODUÇÃO}

Este artigo visa estudar o papel exercido pelo Supremo Tribunal Federal (STF) tendo como foco a interpretação. Primeiramente, foram analisadas algumas pesquisas que trabalharam o papel interpretativo do STF. A Constituição da República de 1988 dispõe que compete ao Supremo Tribunal Federal a guarda da Constituição, mas qual seria o papel que o tribunal vem de fato exercendo no ordenamento jurídico atual?

Utilizou-se a teoria do interpretante apresentada por Edward Lopes em seu livro "Discurso, texto e significação: uma teoria do interpretante" que toma a interpretação como um fato da leitura, o que significa dizer que o leitor também detém o poder sobre o texto extraído do discurso. O texto atribui sentido ao discurso e o discurso, por sua vez, controla o sentido do texto.

São apresentados os postulados epistemológicos da teoria semântica: a sensatez da mensagem - o discurso tem um sentido, a interpretação vai buscar o sentido do discurso no texto -, o caráter oculto do significado - o sentido é algo que se procura dentro da multissignificação continente no discurso - e o mais problemático, a inteligibilidade do sentido - o autor do discurso é o titular da autoridade interpretativa.

A partir desses pressupostos é preciso problematizar a interpretação e o papel do interpretante, a fim de questionar como é feita a interpretacão pelo Supremo Tribunal Federal.

A fim de fazer o uso da semiótica e linguística de maneira a analisar o discurso jurídico e a interpretação jurídica como é feita hoje em dia é necessário fazer um esquadrinhamento de alguns conceitos fundamentais para a compreensão do funcionamento da linguística e da interpretação.

Dessa forma, a intenção deste trabalho é trazer a Teoria do interpretante de Edward Lopes e aplicá-la ao direito de modo a questionar a atuação do Supremo Tribunal Federal e o modo como este vem exercendo a jurisdição constitucional.

Este artigo divide-se em 4 seções. Além desta seção introdutória, a seção 2 traz algumas pesquisas que tratam da atuação do Supremo Tribunal Federal e analisa os argumentos utilizados pelos pesquisadores acerca do posicionamento do Supremo Tribunal Federal. A seção 3 explica a Teoria do Interpretante de Edward Lopes, partindo dos três postulados epistemológicos da teoria semântica e finalizando com os conceitos de interpretante e auctoritas de acordo com sua teoria. E, por fim, na seção 4 encontram-se as considerações finais. 


\section{SUPREMO TRIBUNAL FEDERAL E SUA FUNÇÃO INTERPRETATIVA: O PAPEL DO SUPREMO TRIBUNAL FEDERAL SOB A PERSPECTIVA DA TEORIA DO INTERPRETANTE}

\section{ATUAÇÃO DO SUPREMO TRIBUNAL FEDERAL}

A Constituição da República de 1988, em seu artigo 102, dispõe que compete ao Supremo Tribunal Federal a guarda da Constituição (BRASIL, 1988). Partindo deste pressuposto a pesquisa de Luís Henrique Martins dos Anjos mostra uma teoria de que a interpretação feita pelo Supremo Tribunal Federal é distinta da interpretação hermenêutica. Ele alega que qualquer jurista pode utilizar-se das regras de interpretação do direito a fim de declarar uma norma aplicável.

No entanto, é só o Supremo Tribunal Federal, como guardião da Constituição, quem dispõe da prerrogativa de utilizar a interpretação conforme a Constituição por conta de sua natureza jurídica peculiar de modalidade de controle de constitucionalidade, uma vez que esta interpretação "enquanto técnica de julgamento na via concentrada-abstrata de controle de constitucionalidade fixa a interpretação da Constituição Federal o que é realizado precipuamente pelo Supremo Tribunal Federal" (ANJOS, 2004, p. 1).

Este posicionamento é fundamentado na declaração do Ministro Moreira Alves que afirma que "o princípio da interpretação conforme à Constituição (Verfassungskonforme Auslegung) é princípio que se situa no âmbito do controle de constitucionalidade, e não apenas simples regra de interpretação" (Representação de Inconstitucionalidade $N^{\circ}$ 1417-7 DF, 9 de dezembro de 1987 citado por ANJOS, 2004, p. 2). A interpretação conforme a Constituição é tida, portanto, como um princípio próprio da fiscalização constitucional utilizado como técnica de controle de constitucionalidade.

Entretanto, para ele, esta técnica somente pode ser utilizada no âmbito do juízo abstrato de constitucionalidade de normas, uma vez que os tribunais inferiores não declaram a constitucionalidade ou inconstitucionalidade do ato, mas apenas utilizam a constitucionalidade para aplicar a regra ao caso concreto (ANJOS, 2004, p. 2).

Deste modo, as interpretações feitas pelos juízes seriam a base para uma decisão que respeite as normas constitucionais e não a citada técnica de interpretação conforme a Constituição.

O primeiro argumento utilizado como base para este posicionamento afirma que, por causa da presunção de constitucionalidade das normas, seria necessário que o Supremo Tribunal Federal sempre buscasse, pelo menos a princípio, dar ao texto legal uma interpretação de forma a adequá-lo à Constituição em oposição a uma interpretação que fira a 
Constituição, o que acarretaria em uma declaração de inconstitucionalidade, algo que o autor julga que deve ser evitado (ANJOS, 2004, p. 3).

A primeira vista este argumento é coerente com outros princípios constitucionais, além de ser mais conveniente para o Supremo Tribunal Federal, uma vez que ao invés de julgar o texto legal inconstitucional ele pode flexibilizar a Constituição e adaptar a norma conforme sua compreensão.

Já o segundo argumento está assentado no entendimento de que esta interpretação estaria embasada pelo "princípio da economia do ordenamento" ou "princípio do máximo aproveitamento dos atos jurídicos normativos", segundo o qual se deve dar a máxima validade ao ato jurídico, tentando salvá-lo ao buscar uma interpretação que se enquadre à Constituição, dando ao ato uma aplicação adequada à Constituição, ao invés de declarar o ato inconstitucional (ANJOS, 2004, p. 3).

Apesar da justificativa de Luís Henrique dos Anjos, ambos entendimentos, além de muito similares, levam a um mesmo fim: ao invés de declarar a norma inconstitucional o Supremo Tribunal Federal deve dar ao texto uma interpretação que transforme esta norma, antes inadequada, em algo aplicável ao ordenamento jurídico.

E, ainda que em relação a quesitos práticos, de eficiência e economicidade jurídica e legislativa, estes pensamentos possam fazer sentido, por outro lado é necessário questionar se esta modalidade de interpretação não estaria ampliando certos poderes do Supremo Tribunal Federal ou modificando a interação entre o legislativo e judiciário.

Afinal, se o Supremo Tribunal Federal ao realizar suas funções no âmbito do controle de constitucionalidade não dispõe do poder de criar normas jurídicas diversas das instituídas pelo Poder Legislativo, como poderia ele transformar um enunciado normativo inconstitucional em algo aplicável apenas através da interpretação? Até onde vão os limites desta transformação?

A solução defendida por sua teoria é a de que o primeiro limite que pode ser estabelecido é o limite gramatical. A interpretação do Supremo Tribunal Federal não pode ultrapassar o que está de fato escrito no ato normativo, o limite imposto pela norma escrita, sob pena de substituir seu papel de intérprete pelo de legislador do ato (ANJOS, 2004, p. 3).

O Supremo Tribunal Federal usará a interpretação conforme à Constituição, quando o que se tem certeza é de que a interpretação em questão é constitucional. Por este entendimento, diz o Supremo Tribunal que não precisa ser declarada a inconstitucionalidade da norma impugnada, na medida em que se possa dar uma interpretação adequada com o que estabelece a Constituição. Esta é uma forma de 


\section{SUPREMO TRIBUNAL FEDERAL E SUA FUNÇÃO INTERPRETATIVA: O PAPEL DO SUPREMO TRIBUNAL FEDERAL SOB A PERSPECTIVA DA TEORIA DO INTERPRETANTE}

salvar o ato normativo da declaração de nulidade. É isso que o Supremo faz, ele julga improcedente a ação, declarando que é constitucional o ato impugnado, desde que ele seja aplicado com a interpretação que a Corte definiu. Logo, o Supremo Tribunal Federal determina como deve ser aplicada aquela lei para que ela seja constitucional. (ANJOS, 2004, p. 6)

A conclusão é, portanto, que a não ser que a interpretação não altere o significado ou a concepção original do ato normativo ela será viável (ANJOS, 2004, p. 4). A questão que se impõe é: o que é significado? Como abstrair o significado do enunciado normativo?

Entretanto este limite tem sido flexibilizado também, como pode ser visto na decisão da questão homoafetiva ${ }^{3}$ que, se colocados de lado posicionamentos pessoais acerca do tema, desconsiderou o obstáculo gramatical para considerar que a norma "homem e mulher" pudesse ser utilizada como "duas pessoas".

Ao assumir que a interpretação constitucional é indissociável da argumentação prática moral, Rachel Nigro, se posiciona no sentido oposto deste pensamento, afirmando que as "novas funções" de atuação da corte constitucional são consequência da "judicialização das relações sociais, em oposição ao entendimento de que o ativismo judicial que extrapola os limites do texto" (NIGRO, 2012, p. 158).

Para Nigro, a questão gira em torno da ordem moral, na qual o Supremo Tribunal Federal como intérprete da corte constitucional torna-se co-legislador, reconstruindo o sentido do texto de maneira a produzir normas que não existem, criando direito.

Ela afirma que isso não significa que o Supremo Tribunal Federal esteja inventando normas a partir do nada, ainda que concorde que a decisão da Arguição de Preceito Fundamental - ADPF 132 (BRASIL, 2011) tenha sido contrária ao sentido das palavras utilizadas pelo legislador. Ela afirma que:

Conforme os constitucionalistas não-positivistas - como Dworkin, Alexy, Nino e Atienza -, os sistemas jurídicos constitucionalizados estão atravessados por uma tensão própria ao Estado de Direito e que afeta em cheio a interpretação constitucional. Tal tensão, entre a efetivação dos direitos fundamentais - a realização da justiça - e o respeito à autoridade, traz para a jurisdição constitucional uma difícil conciliação entre um papel ativo, porém limitado pelo sistema jurídico. (NIGRO, 2012, p. 175)

No entanto, o questionamento que se propõe a este respeito é: o Supremo Tribunal Federal é guardião último dos ideais democráticos? Isso se traduz como um guardião da

\footnotetext{
3 Arguição de Preceito Fundamental - ADPF no $132-R J$, de relatoria do Ministro Ayres Brito que tratou da união homoafetiva e seu reconhecimento como instituto jurídico.
} 
moral?

Entretanto, o ponto essencial da discussão está exatamente neste papel "limitado pelo sistema jurídico" da jurisdição constitucional, que é imprescindível num Estado Democrático de Direito. Pois sem o estabelecimento de limites não estaríamos falando deste, mas de outros paradigmas de estado.

O que se questiona não é se o Supremo Tribunal Federal interpreta ou não os atos normativos, porque sim, ele interpreta e deveria fazê-lo, mas se ele está assumindo o papel de interpretante ou de auctoritas ao fazer esta interpretação.

Rachel Nigro propõe ainda uma solução para o questionamento acerca da legitimidade da jurisdição constitucional do modo como tem sido realizada pelo Supremo Tribunal Federal, alegando que

\begin{abstract}
Assim, um tribunal constitucional pode representar o povo argumentativamente e se legitima quando a coletividade o aceita como instância de reflexão racional do processo político. E grande parte da legitimidade da jurisdição constitucional está na capacidade das decisões de uma corte constitucional, através do discurso racional, energizarem o debate público e incrementarem o seu grau de racionalidade. (NIGRO, 2012, p. 169)
\end{abstract}

Colocar o Supremo Tribunal Federal na posição de pináculo da racionalidade do processo político é, no mínimo, questionável.

De qualquer maneira, definir a legitimidade da jurisdição constitucional a partir da capacidade de produzir ou não um discurso racional não é o melhor caminho, ainda que utilizando-se da definição de Alexy de que o papel de interpretação do tribunal é uma representação política exercida argumentativamente como faz Rachel Nigro ao alegar que:

\footnotetext{
Segundo Alexy, o papel do tribunal constitucional na interpretação última de direitos fundamentais é uma representação política, exercida argumentativamente. Isto porque, mais do que corretivos do princípio majoritário, os direitos fundamentais se afirmam hoje como condições estruturantes da própria democracia, devendo permanecer à margem das disputas políticas. (NIGRO, 2012, p. 168)
}

Sob uma outra perspectiva, Vojvodic, Machado e Cardoso apontam para o fato de que "o processo de legitimação da criação e aplicação do direito é bem mais complexo que o dos artifícios de argumentação" (VOJVODIC; MACHADO; CARDOSO, 2009, p. 25).

Não é o fato de que Supremo Tribunal Federal passou a ocupar um papel político de maior destaque e a dialogar mais com os outros poderes que representa um problema, a questão central é que este novo cenário necessita de uma atenção maior sobre o processo 


\section{SUPREMO TRIBUNAL FEDERAL E SUA FUNÇÃO INTERPRETATIVA: O PAPEL DO SUPREMO TRIBUNAL FEDERAL SOB A PERSPECTIVA DA TEORIA DO INTERPRETANTE}

decisório do Tribunal, até mesmo para que seja possível exercer um controle democrático dessas decisões (VOJVODIC; MACHADO; CARDOSO, 2009).

Conforme os estudos realizados por Isis Garcia a partir de decisões do Supremo Tribunal Federal, em que fez um levantamento dos trechos em que os ministros discorrem acerca de seu próprio papel, Garcia conclui que, por vezes, o Supremo demostra uma atitude pretensiosa.

Ela aponta para o fato de que o Supremo Tribunal Federal argumenta que interpretações divergentes feitas pelo Poder Legislador fragilizam a força normativa da Constituição (GARCIA, 2010, p. 123).

Apesar do que acredita o Supremo Tribunal Federal (GARCIA, 2010), a Constituição e sua interpretação não pertencem exclusivamente ao Judiciário. Todos os Poderes políticos detém a responsabilidade sobre os enunciados normativos.

Assim, nenhuma instituição possui a prerrogativa de determinar sozinha no que diz respeito a questões constitucionais, da mesma forma que nenhuma pode submeter a Constituição a seus próprios interesses ou direcioná-la a seus fins políticos (BERCOVICI citado por GARCIA, 2010, p. 123).

\footnotetext{
A relação entre os Poderes com a Constituição deve ser de máxima lealdade, do contrário, o significado de Estado Democrático de Direito não passaria de mais uma falácia, que por sua vez abala as suas estruturas, visto que, a princípio, nenhum Poder pode se sobrepor aos demais, mas não é o que ocorre. (GARCIA, 2010, p. 123-124)
}

O próprio Tribunal se coloca como a palavra última acerca de certos assuntos, se colocando na posição de intérprete legítimo, ou de intérprete maior, como os próprios ministros se denominam, chegando ao ponto de desconsiderar qualquer interpretação de instâncias inferiores que contradigam seu entendimento. Conforme pode ser visto no seguinte julgado:

Contrariamente, a manutenção de soluções divergentes, em instâncias inferiores, sobre o mesmo tema, provocaria, além da desconsideração do próprio conteúdo da decisão desta Corte, última intérprete do texto constitucional, a fragilização da força normativa da Constituição. (RE AGR 328812, fls. 5 citado por GARCIA, 2010, p. 124)

Ao dizer que contrariar o entendimento da Corte significa fragilizar a força normativa da Constituição o Tribunal está, a seu modo, dando a si próprio e ao seu 
entendimento um tratamento como se fosse ele a própria Constituição.

De acordo com Garcia, o Supremo Tribunal Federal, ao pretender decidir em última instância de forma vinculada assume um papel de superioridade que passa a tomar proporções de um poder soberano, transformando a Constituição em um documento que pode, a todo momento, ser reescrito pelo juiz constitucional, o que ela afirma transformá-la em uma “Constituição jurisprudencial” (GARCIA, 2010, p. 124).

Garcia traz à tona os ensinamentos de Ferraz Jr. para explicar que a interpretação do legislador é um dever-ser que não tem caráter de norma, mas explica que a interpretação judicial, por sua vez, ao definir o sentido de um enunciado normativo estabelece suas balizas, através de um ato de vontade (GARCIA, 2010, p. 124-125).

De acordo com o Supremo Tribunal Federal é ele quem fixa a exata interpretação das normas, conforme relatado em Arguição de preceito fundamental "a Corte fixará a exata exegese e compreensão da regra" (ADPF 4 MC, fls. 35, Ministro Néri da Silveira citado por GARCIA, 2010, p. 125).

Por óbvio o que se pretende não é afirmar que o Supremo Tribunal Federal não deva interpretar as leis ou que ele adote uma posição legalista onde os ministros sejam meros serviçais da vontade da lei, mas sim que esta é uma das atividades do Tribunal e que ela deve realizada através de técnicas argumentativas coerentes e critérios rigorosos de fundamentação, como bem explica Isis Garcia, que afirma que o esquecimento destes requisitos pode acarretar em despropósitos decisionistas.

Ela ainda acrescenta que a falha nas fundamentações das decisões do Supremo podem ser uma forma de esconder seus "pré-conceitos" (GARCIA, 2010). Nas palavras da professora:

É interessante notar, desde logo, que a partir da perspectiva de que os Ministros são
os "intérpretes maiores", "os guardiões da Constituição", que sua função é a de
"exegeta maior"; assim como, não há uma sistematização na forma em que decidem,
mas apenas certos lugares comuns argumentativos utilizados pelos magistrados, não
seria precipitado, pois, dizer que há um discurso/escudo "Guarda da Constituição".
Este é utilizado em qualquer momento, a fim de legitimar suas decisões, ou seja,
este discurso/escudo pode estar ocultando as pré-compreensões dos Ministros do
Supremo Tribunal Federal. (GARCIA, 2010, p. 129)

Sob argumento de "intérprete maior" os ministros conseguem englobar uma gama vasta de decisões que, parecem acreditar, seja suficiente para dispensar uma justificativa mais elaborada para embasar seus posicionamentos, de forma a flexibilizar a Constituição quando 


\section{SUPREMO TRIBUNAL FEDERAL E SUA FUNÇÃO INTERPRETATIVA: O PAPEL DO SUPREMO TRIBUNAL FEDERAL SOB A PERSPECTIVA DA TEORIA DO INTERPRETANTE}

necessário.

Apesar de ser uma alegação séria, esta é uma questão que merece atenção, por conta não só da visibilidade que o tribunal possui atualmente, mas da força que suas decisões ganharam. E porque este ponto está ligado diretamente a princípios basilares do Estado Democrático de Direito sem os quais toda a estrutura de garantia constitucional não prospera.

Apesar de ser uma maneira de diminuir o número alarmante de processos existentes, a súmula vinculante aumenta o poder discricionário do Supremo Tribunal Federal e enfraquece os tribunais inferiores que têm suas funções reduzidas a aplicadores de súmulas. Como afirma Lênio Streck "o poder sendo exercido sem freios e contrapesos, tudo porque as Súmulas vinculantes transformam-se, na prática, de normas individuais - válidas para cada caso - em normas gerais de validade erga omnes" (STRECK citado por GARCIA, 2010, p. 128).

O Supremo Tribunal Federal não é única fonte do direito e colocar as súmulas vinculantes e jurisprudências do STF como algo imutável que deve sempre ser aplicado pelos juízes das instâncias inferiores tira deles o papel de interpretantes do direito, bem como dos demais que atuam no processo, e colocam as decisões do Supremo Tribunal Federal num patamar diferenciado hierarquicamente maior.

\section{INTERPRETANTE E AUCTORITAS}

A Teoria do interpretante proposta por Lopes, apesar de se utilizar do termo “interpretante" não está afiliada aos conceitos de Peirce sobre o tema.

Para Peirce, todo signo se estabelece a partir de relações que envolvem seu fundamento, suas relações com aquilo a que representa, seu objeto (ou referente) e com os efeitos que gera, chamados interpretantes. E a chamada tríade semiótica de Peirce (PEREZ, 2004, p. 141).

No entanto, Lopes toma a interpretação como um fato da leitura, o interpretante de Lopes se limita a descrever os procedimentos empíricos através dos quais um discurso conotado se transforma em denotado (LOPES, 1978, p. 1).

$\mathrm{O}$ interpretante faz a passagem do sentido figurado para o literal. E, de acordo com a teoria defendia por Lopes, todo discurso é figurado e é a interpretação que o leva ao sentido literal. 
Tomar a interpretação como um fato da leitura significa dizer que o leitor, ou como empregado por Lopes, o destinatário da mensagem, também detém o poder sobre o texto extraído do discurso. O texto atribui sentido ao discurso e o discurso, por sua vez, controla o sentido do texto.

É importante destacar que para os fins deste artigo o termo "texto" não possui a conotação habitual de "conjunto de palavras, de frases escritas [...] texto manuscrito ou impresso (em oposição a ilustração)" (FERREIRA, 2004, p. 1946). Ele é aqui utilizado como o topos de onde se retira o sentido do discurso.

Discurso, por sua vez, mantém parte da definição encontrada no dicionário de "manifestação concreta da língua. [...] Unidade linguística maior do que a frase; enunciado" (FERREIRA, 2004, p. 686), mas aqui em uma versão mais específica ou até mais aprofundada. Conforme Lopes: "Se do ponto de vista linguístico, o discurso é um objeto semiótico ultilizado para dizer alguma coisa, do ponto de vista pragmático ele é um objeto prático utilizado para fazer alguma coisa" (LOPES, 1978, p. 9).

Lopes parte da ideia de que existem certos postulados sobre os quais as teorias semânticas se assentam, ainda que de maneira implícita. Destes postulados, ele elenca os três mais comuns, e que servirão de ponto de partida para o desenvolvimento de sua teoria.

O postulado da sensatez da mensagem afirma que o discurso contém um sentido, ou ainda, que todo discurso possui sentido. Claro que isto não significa que o discurso possui, por si só, um sentido, caso assim fosse não haveria necessidade de interpretação (LOPES, 1978). Portanto, para que seja passível de interpretação é necessário que o discurso possua um sentido, a ser "captado" dele.

No entanto, dizer que para captar o sentido do discurso é necessária a interpretação é dizer que seu sentido está em um espaço que transcende o discurso, espaço este que é chamado de texto (LOPES, 1978). O que a interpretação faz é ir buscar no texto o sentido do discurso.

Uma vez afastada a hipótese da inexistência de sentido no discurso, o segundo postulado apresenta, por outro lado, que há um excesso de sentidos dentro do discurso.

É a chamada multissignificação do discurso, na qual o discurso (objeto de conhecimento) fica aberto a uma pluralidade de leituras, cada qual possuindo uma quantidade de textos possíveis.

O caráter oculto do significado quer dizer, portanto que é preciso procurar pelo sentido num mar de possibilidades e leituras possíveis, que Edward Lopes compara a uma 


\title{
SUPREMO TRIBUNAL FEDERAL E SUA FUNÇÃO INTERPRETATIVA: O PAPEL DO SUPREMO TRIBUNAL FEDERAL SOB A PERSPECTIVA DA TEORIA DO INTERPRETANTE
}

floresta, onde a árvore (o sentido) tem a sua singularidade escondida pelo conjunto da floresta, como se "uma pluralidade de sentidos ocultasse um sentido único" (LOPES, 1978, p. $3)$.

\begin{abstract}
Assim é que a teoria semântica de todos os tempos reconheceu como axiomática a multissignificação do discurso, objeto de conhecimento aberto a uma pluralidade de leituras, continente, pois, de $n$ textos. [...] Objetos alegóricos, a floresta e o discurso seriam modos da manifestação figurativa de um "não saber" que é eminentemente perturbador. (LOPES, 1978, p. 3)
\end{abstract}

A quantidade excessiva de sentidos foge ao domínio do leitor, pois não há como conhecer todos eles, portanto o fato de ter sentidos demais é o que faz do discurso algo conotado, desconhecido. Por isso a passagem do discurso para o texto é a passagem do nãosaber para o saber.

O postulado da inteligibilidade do discurso tenta resolver o problema que surge com a existência de inúmeros sentidos para um mesmo discurso.

De acordo com este postulado o autor do discurso é o titular da autoridade da interpretação, sendo o discurso objeto daquele que o produz ele seria o único capaz de dizer o que seu discurso significa. Deste modo, a solução se dá ao entregar ao autor o poder de escolha do sentido de seu discurso.

O problema de colocar sobre o autor do discurso a única autoridade para interpretação é que

\begin{abstract}
A locação da autoria do discurso fazia-se acompanhar, então, de uma espécie de sublocação de "autoria do texto", pois que só ao produtor da mensagem era reconhecida a competência necessária para definir, de um lado, o que seu discurso queria dizer, ou o que ele podia dizer, e, por outro lado, o que ele, efetivamente, dizia. Diante de interpretações indesejáveis, feitas por um destinatário, o destinador da mensagem poderia sempre atribuir o subentendido à malevolente inépcia do ouvinte, operando, desse modo, a desqualificação do subentendido para requalificálo como mal-entendido. (LOPES, 1978, p. 4)
\end{abstract}

Esta ideia muito se assemelha à máxima "sou responsável pelo que eu digo, não pelo que você entende" como forma de exoneração de responsabilidade do discurso dito, onde o autor conta com a possibilidade de esquivar-se de possíveis interpretações de seu discurso sem se tornar responsável pelos textos que este produziu.

O autor do discurso continuava a manter seu poder sobre o discurso mesmo depois de transmitido, ele podia inclusive manipular o sentido do discurso como melhor lhe provia e 
mudar de ideia ao longo do caminho, pois era ele o detentor do poder de dizer o que significava seu discurso. $\mathrm{O}$ autor era detentor do que o discurso queria dizer e do que o discurso efetivamente dizia.

O texto estava firmado na pessoa do produtor do discurso, colocando a multissignificação do discurso a serviço de um privilégio de mando de uma auctoritas absoluta (única e indiscutível) apenas camuflada como privilégio de significação.

Existe uma estreita relação entre a comunicação e a ideologia, afinal é através da língua natural que o grupo transfere seu sistema de valores grupalmente compartilhados.

Neste sentido, Edward Lopes deduz que caso houvesse uma teoria a observar o que as pessoas fazem com as palavras quando se comunicam umas com outras ela culminaria em uma teoria da ideologia, que, por sua vez, trataria do que as pessoas fazem com outras pessoas quando se utilizam de palavras (LOPES, 1978, p. 4).

A manipulação dos sentidos seria, então, o método de dominação mais eficiente já inventada pelo homem. Pois aquele que manipula os sentidos do discurso é quem irá definir o que é valor e antivalor dentro de uma sociedade, ditando quais as regras de comportamento devem ser seguidas, bem como apontando no sentido de quais os objetivos devem ser almejados e quais devem ser prioridade, provido de uma carga axiológica grande é ele quem vai punir ou recompensar os comportamentos sociais de modo a orientar a ação singular dos indivíduos. Ele se transforma, deste modo, no árbitro todo-poderoso da comunidade (LOPES, 1978, p. 4).

Para Edward Lopes, uma das maiores contribuições da linguística enquanto ciência está na lição de Jakobson que visa modificar essa situação de dominação através da manipulação dos sentidos ao "insistir no fato de que a semântica deve se preocupar com o sentido do discurso tal como ele se deixa codificar no interior do código que serviu para a sua codificação" (LOPES, 1978, p. 5). Ou seja, o sentido do discurso considerando a mensagem e não a pessoa que a produziu.

Num discurso poético é possível a convivência de dois discursos distintos, cada um com seu texto correspondente, uma vez que a forma como são dispostos os signos podem (e muitas vezes este é o intuito) ensejar leituras simultâneas de mais de uma isotopia - plano de sentido.

Nestes casos há o que Lopes chama de "multiarticulação de vários significantes sobrepostos no mesmo plano de expressão com vários significados" (LOPES, 1978, p. 6). Ou seja, palavras sobrepostas de uma maneira tal que sua leitura produza sentidos distintos, mas 


\section{SUPREMO TRIBUNAL FEDERAL E SUA FUNÇÃO INTERPRETATIVA: O PAPEL DO SUPREMO TRIBUNAL FEDERAL SOB A PERSPECTIVA DA TEORIA DO INTERPRETANTE}

que, entretanto são complementares, convivem de maneira harmônica e são todos bem vindos ao plano de expressão literário.

No âmbito do direito estas leituras simultâneas em vários planos de sentido não costumam ocorrer com a mesma facilidade, visto que os fins do discurso jurídico são diferentes do poético.

Ainda assim, é esta multiarticulação que autoriza à linguística a definir o discurso como o espaço onde ocorrem os processos de significação.

O discurso é primeiro o resultado do fazer do destinador (ao invés de autor - como aquele que detém a autoridade), ao produzir o discurso o destinador realiza toda uma produção de significados e o texto produzido a partir deste discurso se torna o espaço deste processo de significação.

Por outro lado, no momento em que o destinatário faz a leitura deste mesmo discurso ele o refaz e, ao refazer aquele discurso, o destinatário produz um texto. De forma que o texto é o resultado do fazer do destinador e do refazer (na leitura) do destinatário. Ou seja, o interpretante.

A obra surge, então, como o espaço onde ocorre o processo de significação através do ciclo: discurso que produz texto e o texto, produzido pelo discurso, é produtor daquilo que o produziu.

Assim, o texto responde às indagações do discurso, captando um sentido dele, o discurso, por sua vez, (co-)responde àquela interpretação, ele responde à interpretação do texto validando aquela interpretação ou rejeitando-a.

O ponto focal deste movimento é que a rejeição ou validação de um texto é feita pelo discurso que corresponde, trabalha em conjunto, na produção de significado. É a análise linguística do discurso que dirá se aquele texto é ou não um saber, diferentemente quando o autor/autoridade decide. O discurso aponta para os elementos linguísticos do código para atestar a veracidade do texto e aceitá-lo, reabsorvendo-o como um saber.

O auctoritas interrompe este movimento, impedindo que a produção de significado se dê através da validação de um texto extraído do discurso por meio da decodificação. A autoridade entrega a interpretação que lhe convém e não existe possibilidade de verificação de sua veracidade. É por estar vinculada à autoridade que a interpretação é recebida como um saber. 


\section{CONSIDERAÇÕES FINAIS}

Uma mensagem, quando produzida, já vem cheia de possibilidades de sentido. Quem indica essas possibilidades não deveria ser a pessoa que criou o discurso. Caso o destinador da mensagem queira reduzir as múltiplas possibilidades de interpretação do seu discurso ele deve escrevê-lo de forma a alcançar este objetivo, fazendo um discurso mais claro e menos ambíguo possível, de modo que a produção de significados na feitura do discurso (a semiose realizada) almeje este fim.

Mas, uma vez pronto o discurso, o destinador não deveria ter mais o poder de dizer o que este quis ou não dizer, ou qual tex to é válido ou não. Ele não deveria poder mais controlar os textos produzidos a partir do discurso, sob pena de dar ao destinador um excesso de poder (de autor/autoridade), um poder excessivo a uma só pessoa (ou a poucas), pois ela terá o poder da manipulação dos sentidos que gera uma dominação social.

Esta forma de interpretação remonta aos antigos. É um modo antiquado de interpretar e que coloca todo o poder sobre aquele que escreveu a mensagem, o autor do discurso, é uma interpretação flutuante, varia de acordo com a autoridade que interpreta e dita as regras de forma axiológica.

O modo como se faz a interpretação das leis hoje está baseado nas pessoas e não no código. O STF, ao invés de interpretante, tomou o papel de autoridade, substituindo, inclusive o real autor das leis (o legislativo).

É um modo antiquado de interpretar e que coloca todo o poder em cima daquele que escreveu a mensagem, o autor do discurso (no caso das leis o legislador) ou então, no caso brasileiro atual, nem do autor, mas do STF, este terceiro que não é o destinador do discurso e que interpreta com pretensões de autor/autoridade. Sem um código que torne mais objetivo o método para interpretar, transforma-se em uma interpretação flutuante, que varia de acordo com aquele que interpreta e dita as regras de forma axiológica.

Uma vez feito o discurso e lançado este no mundo "real" seria preciso usar uma codificação para encontrar o sentido dele. Essa codificação se encontra na própria estrutura da língua, na nossa gramática internalizada, nos sentidos que o discurso nos traz dentro da estrutura da língua e, dentro destas possibilidades, olhar para o todo das normas para verificar quais sentidos são verdadeiros e possíveis.

A partir daí é necessário analisar se dentro desses possíveis sentidos estão os objetivos do legislador. Pois, ou faz-se uma nova lei, escrita de uma forma mais clara, 


\section{SUPREMO TRIBUNAL FEDERAL E SUA FUNÇÃO INTERPRETATIVA: O PAPEL DO SUPREMO TRIBUNAL FEDERAL SOB A PERSPECTIVA DA TEORIA DO INTERPRETANTE}

reescreve-se a lei para alcançar o objetivo almejado, ou então deverão ser aceitos todos os sentidos possíveis.

Não se pode ter uma interpretação extensiva em alguns casos e restritivas em outros com argumentos amplos ou pessoais demais, baseados nas opiniões de quem interpreta exercendo um papel de autoridade.

Quando o Supremo Tribunal Federal afirma que contrariar o entendimento da Corte é fragilizar a força normativa da Constituição, o que se está afirmando é que este, e seu entendimento, é a própria Constituição. Não se considerando, assim, como interpretantes da Constituição, mas como o próprio autor/autoridade, o denominado auctoritas.

Sim, o Supremo Tribunal Federal interpreta a Constituição e ao fazer ele refaz o texto através da leitura, no entanto ele não pode extrapolar certos limites e também ele não pode ser o único a fazer isso, colocando toda e qualquer interpretação que não venha dele em cheque.

O que o Tribunal vem fazendo é interpretar exercendo uma função de intérprete maior, que pode ser denominada como uma espécie de auctoritas, ao invés de exercer uma função de interpretante.

\section{REFERÊNCIAS}

ANJOS, Luís Henrique Martins dos. A interpretação conforme a constituição enquanto técnica de julgamento do Supremo Tribunal Federal. Debates em Direito Público: revista de Direito dos Advogados da União, v. 3, n. 3, p. 127-139, out. 2004. Disponível em: <http://egov.ufsc.br/portal/sites/default/files/anexos/15728-15729-1-PB.pdf>. Acesso em: 20 jan. 2018.

BRASIL. Constituição (1988). Constituição da República Federativa do Brasil. Brasília: Senado, 1988.

BRASIL. Supremo Tribunal Federal. Arguição de Descumprimento de Preceito Fundamental 132. Brasília, 14 de ot. 2011. Disponível em: $<$ http://redir.stf.jus.br/paginadorpub/paginador.jsp?docTP=AC\&docID=628633 $>$. Acesso em: 02 de ago. 2018.

FERREIRA, Aurélio Buarque de Holanda. Novo dicionário Aurélio da língua portuguesa. 3. ed. Curitiba: Positivo, 2004.

GARCIA, Isis Jesus. O Supremo Tribunal Federal é o intérprete maior: reflexões acerca do decisionismo. In: Revista da Faculdade de Direito UFG, V.34, n. 02, p. 122-135 , jul. / dez. $2010 \quad$ ISSN $\quad 0101 \quad-\quad 27187 \quad$ Disponível <https://www.revistas.ufg.br/revfd/article/view/10031/9532>. Acesso em: 20 jan. 2018. 
LOPES, Edward. Discurso, texto e significação: uma teoria do interpretante. São Paulo: Cultrix, 1978.

NIGRO, Rachel. A decisão do Supremo Tribunal Federal sobre a união homoafetiva: uma versão pragmática da linguagem constitucional. In: Direito, Estado e Sociedade. n.41 p. 157 a 183, jul/dez 2012. Disponível em: <http://www.jur.pucrio.br/revistades/index.php/revistades/article/view/158>. Acesso em: 20 jan. 2018.

PEREZ, Clotilde. Signos da Marca: expressividade e sensorialidade. São Paulo: Thomson Learning, 2004.

VOJVODIC, Adriana de Moraes; MACHADO, Ana Mara França; CARDOSO, Evorah Lusci Costa. Escrevendo um romance, primeiro capítulo: precedentes e processo decisório no Supremo Tribunal Federal. In: Revista Direito GV, São Paulo, p. 021-044, jan/jun 2009. Disponível em: <http://www.scielo.br/scielo.php?pid=S180824322009000100002\&script=sci_abstract\&tlng= pt>. Acesso em: 20 jan. 2018. 